\title{
Predicting type 2 diabetes mellitus and insulin resistance
}

\author{
V. Mohan
}

Received: 13 December 2011 / Accepted: 16 December 2011 /Published online: 29 March 2012

(C) Research Society for Study of Diabetes in India 2012

Type 2 diabetes has now become a global health problem threatening the lives of millions of people. According to the latest Diabetes Atlas 5, released on 14th November 2011 by the International Diabetes Federation (IDF), there are currently 366 million people with diabetes globally and this is predicted to increase to 552 million by the year 2030 [1]. Unfortunately, type 2 diabetes is a silent disease. In the Chennai Urban and Rural Epidemiology Study (CURES), it was shown that the "Rule of Halves" is very much valid in the case of diabetes [2] just as in the case of hypertension [3]. Thus, half of those with type 2 diabetes in the community remain undiagnosed, of those diagnosed, less than half receive treatment and of those who take treatment, less than half have their diabetes under control [2]. One of the challenges for physicians and diabetologists therefore, is to detect undiagnosed type 2 diabetes in the community. Obviously, one way to do it is to screen everyone in the population for the disorder. In a country like India, however, this is not feasible due to sheer numbers of people with diabetes. According to the recent ICMR -INDIAB study, there are an estimated 62.4 million people with diabetes and 77 million people with pre-diabetes [4]. Hence the challenges of screening 1.2 billion Indians to identify all those with diabetes and pre-diabetes can well be imagined. There is therefore a need to develop simple tools to cost effectively identify type 2 diabetes in the population. This led to the establishment of several risk scores for diabetes such as the American Diabetes Association Risk Score [5] Finnish Diabetes Risk Score [6], German Diabetes Risk Score [7],

\footnotetext{
V. Mohan $(\bowtie)$

Dr. Mohan's Diabetes Specialities

Centre \& Madras Diabetes Research Foundation,

4, Conran Smith Road, Gopalapuram,

Chennai 600 086, India

e-mail: drmohans@diabetes.ind.in
}

Danish Diabetes Risk Score [8] Cambridge Risk Score [9] and the Spanish Risk Score [10]. Within India also different risk scores have been described based on population based studies $[11,12]$. It has been shown that the Indian Diabetes Risk Score (IDRS) is useful not only to predict undiagnosed diabetes in the community [11] but also to predict incident diabetes [13], to classify the type of diabetes [14] and even to predict individuals who may have certain complications of diabetes like peripheral vascular disease and neuropathy [15]. The IDRS also serves as an effective indicator of metabolic syndrome and cardiovascular risk even among subjects with normal glucose tolerance [16]. Use of IDRS is more effective and less expensive than genotyping and makes it less costly than universal OGTT screening of the whole population to detect subjects with type 2 diabetes in India [17]. Thus it is clear that diabetes risk scores have come to stay, and if used judiciously, can lead to cost effective screening of diabetes.

While insulin secretory defects are common in all forms of diabetes, insulin resistance remains its hallmark of type 2 diabetes [18]. Several authors have tried to describe simple tools to predict insulin resistance in the community. In this issue of IJDDC, Srisung et al [19] describe the performance of four categories of risk scores in predicting insulin resistance in Thai adults. The four categories are (i) The Royal College of Physicians of Thailand (ii) Thailand Ministry of Public Health, (iii) the risk score of Aekplakorn et al and (iv) the risk score of Keesukpham et al. The Royal College of Physicians of Thailand Score includes almost all the criteria of metabolic syndrome (MS) such as history of hypertension, HDL cholesterol, triglycerides and IGT or IFG. The Thailand Ministry of Public Health criteria is also on similar lines. Using such sophisticated systems including laboratory investigations does not appear to be suitable for mass screening for diabetes or insulin resistance. However, the 
Aekplakorn and the Keesukpham criteria are much simpler and are based on simple anthropometry and historical details and hence would be much more cost effective. It is to be appreciated that the Aekplakorn criteria, in spite of not including biochemical details such as HDL cholesterol, triglycerides or IFG or IGT, performs better than the other scores. The study by Srisung et al is therefore a valuable contribution to the existing knowledge on the subject. However, one of the issues with this study is the female excess (almost $81 \%$ of the subjects studied were females) which is a serious limitation as the applicability to males would need to be established further.

One of the guiding principles behind using risk scores, is that it must be simple and inexpensive so that it can be applied at a population level for public health workers. It should also be easy to use by non-medical people, if it is to gain wide acceptance. For research purposes, sophisticated tests for diagnosing insulin resistance such as the euglycemic clamp technique or the Frequently Sampled Intravenous Glucose Tolerance Test (FSIVGTT) remain the gold standard [20]. However these tests are laborious, require large volumes of blood to be drawn, are observer dependent and need specialized training. Hence they are clearly unsuitable for large scale screening for epidemiological or public health purposes. Hence simpler tools are necessary.

The use of fasting insulin and the homeostatic model assessment (HOMA - IR) have widely been used for epidemiological studies [21]. However, the insulin assay is expensive and also needs careful standardization. Finally, they are not useful for people who already have diabetes particularly if treated with insulin injections and they are therefore best applied in a non-diabetic population. Hence, the necessity of simple risk scores to predict insulin resistance. It is here, that the paper by Srisung et al [19] where they describe the usefulness of the Aekplakorn criteria to assess insulin resistance, becomes important. It is obvious that risk scores are ethnic specific [22] as they are derived from the populations in which they have been tested. Hence using the risk score described in one country or region for another ethnic group or another region of the world, may not be appropriate and each region should ideally have its own risk score.

Use of risk scores are particularly important as they can help to cost effectively screen for diabetes. We have shown that IDRS can help in cost effective screening for diabetes in India as it uses simple, safe and inexpensive measures. Moreover it would help to do selective screening instead of universal screening. For example, if we were to screen a population of $1,00,000$ adults in a city using a $2 \mathrm{~h}$ post load plasma glucose, assuming the cost of one glucose estimation including blood collection to be Rs.30/-, the cost would work out to Rs.30,00,000. For the same population, if a two step procedure is used for screening for diabetes, i.e. use IDRS first and then screen only those likely to have diabetes, only $43 \%$ of the population who have a score $\geq 60$, will have to be screened. This would capture over $72 \%$ of the undiagnosed diabetic subjects. If the screening test is carried out on all these individuals then the cost would work out to Rs.12,90,000. Even if we add a cost of Rs.1,50,000 for collecting information on IDRS, the overall cost would only work out to Rs.14,40,000. Thus there would be a cost saving of almost $50 \%$, which in this case, is Rs. $15,60,000$. Thus, using IDRS would help to drastically reduce the costs of screening for diabetes at a community level [23].

In summary, the use of simple clinical risk scores can help not only in cost effective screening for undetected type 2 diabetes, but also in its classification as well as to identify insulin resistance and metabolic syndrome in the community.

\section{References}

1. 5th Edition of Diabetes Atlas. International Diabetes Federation. http://www.idf.org/diabetesatlas/. Accessed on November 30, 2011.

2. Deepa R, Shanthirani CS, Pradeepa R, Mohan V. Is the "Rule of Halves" in hypertension still valid?-Evidence from the Chennai urban Population Study (CUPS). J Assoc Physicians India. 2003;51:153-7.

3. Smith WC, Lee AJ, Crombie IK, Tunstall-Pedoe H. Control of blood pressure in Scotland: the rule of halves. BMJ. 1990;300:981-3.

4. Anjana RM, Pradeepa R, Deepa M, Datta M, Sudha V, Unnikrishnan $\mathrm{R}$, et al. On behalf of the ICMR-INDIAB Collaborative Study Group. Prevalence of diabetes and prediabetes (impaired fasting glucose and/or impaired glucose tolerance) in urban and rural India: Phase I results of the Indian Council of Medical Research-INdia DIABetes (ICMR-INDIAB) study. Diabetologia. 2011;54:3022-7.

5. ADA diabetes risk score. www.diabetes.org.

6. Lindstrom J, Tuomilehto J. The diabetes risk score: a practical tool to predict type 2 diabetes risk. Diabetes Care. 2003;26:725-31.

7. Schulze MB, Hoffmann K, Boeing H, Linseisen J, Rohrmann S, Möhlig M, et al. An accurate risk score based on anthropometric, dietary, and lifestyle factors to predict the development of type 2 diabetes. Diabetes Care. 2007;30:510-5.

8. Glumer C, Carstensen B, Sandbaek A, et al. Danish diabetes risk score for targeted screening: the Inter99 study. Diabetes Care. 2004;27:727-33.

9. Simmons RK, Harding AH, Wareham NJ, Griffin SJ. EPICNorfolk Project Team. Do simple questions about diet and physical activity help to identify those at risk of type 2 diabetes? Diabet Med. 2007;24:830-5.

10. Long J, Rozo-Rivera A, Akers T, VanGeest JB, Bairan A, Fogarty KJ, Sowell R. Validating the utility of the Spanish version of the American Diabetes Association Risk Test. Clin Nurs Res. 2006;15:107-18.

11. Mohan V, Deepa R, Deepa M, Somannavar S, Datta M. A simplified Indian Diabetes Score for screening for undiagnosed diabetic subjects. (CURES-24). J Assoc Physicians India. 2005;53:759-63.

12. Ramachandran A, Snehalatha C, Vijay V, Wareham NJ, Colagiuri S. Derivation and validation of diabetes risk score for urban Asian Indians. Diabetes Res Clin Pract. 2005;70:63-70. 
13. Mohan V, Deepa M, Anjana RM, Lanthorn H, Deepa R. Incidence of diabetes and pre-diabetes in a selected urban South Indian population (CUPS-19). J Assoc Physicians India. 2008;56:1527.

14. Sharma KM, Ranjani H, Nguyen H, Shetty S, Datta M, Narayan $\mathrm{KM}$, Mohan V. Indian Diabetes Risk Score helps to distinguish type 2 from non-type 2 diabetes mellitus (GDRC-3). J Diabetes Sci Technol. 2011;5:419-25.

15. Mohan V, Vassy JL, Pradeepa R, Deepa M, Subashini S. The Indian Type 2 Diabetes Risk Score also helps identify those at risk of macrovasvular disease and neuropathy (CURES-77). J Assoc Physicians India. 2010;58:430-3.

16. Mohan V, Sandeep S, Deepa M, Gokulakrishnan K, Datta M, Deepa R. A diabetes risk score helps identify metabolic syndrome and cardiovascular risk in Indians- the Chennai Urban Rural Epidemiology Study (CURES-38). Diabetes Obes Metab. 2007;9:337-43.

17. Mohan V, Goldhaber-Fiebert JD, Radha V, Gokulakrishnan K. Screening with OGTT alone or in combination with the Indian Diabetes Risk Score or genotyping of TCF7L2 to detect undiagnosed type 2 diabetes in Asian Indians. Indian J Med Res. 2011;133:294-9.
18. Gerich JE. Contributions of insulin-resistance and insulinsecretory defects to the pathogenesis of type 2 diabetes mellitus. Mayo Clin Proc. 2003;78:447-56.

19. Srisung W, Saprungruang A, Jiamjarasrangsi W. Performance of four risk scores for predicting insulin resistance in Thai adults. Int $\mathrm{J}$ Diab Dev Ctries. 2012. doi:10.1007/s13410-012-0066-2

20. Bergman RN, Prager R, Volund A, Olefsky JM. Equivalence of the insulin sensitivity index in man derived by the minimal model method and the euglycemic glucose clamp. J Clin Invest. 1987;79:790-800.

21. Matthews DR, Hosker JP, Rudsenski AS, Naylor BA, Treacher DF, Turner RC. Homeostasis model assessment: insulin resistance and $\beta$ cell function from fasting plasma glucose and insulin concentrations in man. Diabetologia. 1985;28:412-9.

22. Buijsse B, Simmons RK, Griffin SJ, Schulze MB. Risk assessment tools for identifying individuals at risk of developing type 2 diabetes. Epidemiol Rev. 2011;33:46-62.

23. Mohan V, Pradeepa R, Deepa M, Anjana RM, Unnikrishnan RI, Datta M. How to detect the millions of people in India with undiagnosed diabetes cost effectively. In: Medicine Update. Rao MS (Ed), The Association of Physicians of India, 2010; 20:9396. 